\title{
Article \\ A Phase II Study on the Use of Convalescent Plasma for the Treatment of Severe COVID-19- A Propensity Score-Matched Control Analysis
}

\author{
Vasiliki Pappa ${ }^{1, *}$, Anthi Bouchla ${ }^{1}$, Evangelos Terpos ${ }^{2}\left(\mathbb{D}\right.$, Thomas P. Thomopoulos ${ }^{1}$, Margherita Rosati ${ }^{3}$, \\ Dimitris Stellas ${ }^{3,4}{ }^{\oplus}$, Anastasia Antoniadou ${ }^{5}$, Andreas Mentis ${ }^{6}$, Sotirios G. Papageorgiou ${ }^{1}\left(0\right.$, Marianna Politou ${ }^{7}$, \\ Anastasia Kotanidou ${ }^{8}{ }^{\circ}$, Ioannis Kalomenidis ${ }^{8}\left(\mathbb{D}\right.$, Garyfalia Poulakou ${ }^{9}$, Edison Jahaj ${ }^{8}$, Eleni Korompoki ${ }^{2}$, \\ Sotiria Grigoropoulou ${ }^{5}$, Xintao $\mathrm{Hu}^{10}{ }^{1}$, Jenifer Bear ${ }^{10}$, Sevasti Karaliota ${ }^{3,11}$, Robert Burns ${ }^{10}$, Maria Pagoni ${ }^{12}$, \\ Ioannis Trontzas ${ }^{9}$, Elisavet Grouzi ${ }^{13}$, Stavroula Labropoulou ${ }^{6}$, Kostantinos Stamoulis ${ }^{14}$, Aristotelis Bamias ${ }^{1}{ }^{1}$, \\ Sotirios Tsiodras ${ }^{5}$, Barbara K. Felber ${ }^{10}$, George N. Pavlakis ${ }^{3,+}$ and Meletios-Athanasios Dimopoulos ${ }^{2,+}$ (1)
}

1 Hematology Unit, Second Propaedeutic Department of Internal Medicine and Research Institute, School of Medicine National and Kapodistrian University of Athens, University General Hospital "Attikon", 18120 Athens, Greece; anthibouhla@hotmail.com (A.B.); th.thomopoulos@gmail.com (T.P.T.); sotirispapageorgiou@hotmail.com (S.G.P.); abamias@med.uoa.gr (A.B.)

2 Department of Clinical Therapeutics, School of Medicine, National and Kapodistrian University of Athens, 11528 Athens, Greece; eterpos@med.uoa.gr (E.T.); e.korompoki@imperial.ac.uk (E.K.); mdimop@med.uoa.gr (M.-A.D.)

Citation: Pappa, V.; Bouchla, A.; Terpos, E.; Thomopoulos, T.P.; Rosati, M.; Stellas, D.; Antoniadou, A.; Mentis, A.; Papageorgiou, S.G.; Politou, M.; et al. A Phase II Study on the Use of Convalescent Plasma for the Treatment of Severe COVID-19- A Propensity Score-Matched Control Analysis. Microorganisms 2021, 9, 806. https://doi.org/10.3390/ microorganisms 9040806

Academic Editor: Teresa Santantonio

Received: 20 March 2021

Accepted: 9 April 2021

Published: 11 April 2021

Publisher's Note: MDPI stays neutral with regard to jurisdictional claims in published maps and institutional affiliations.

Copyright: (c) 2021 by the authors. Licensee MDPI, Basel, Switzerland. This article is an open access article distributed under the terms and conditions of the Creative Commons Attribution (CC BY) license (https:/ / creativecommons.org/licenses/by/ $4.0 /$ )
3 Human Retrovirus Section, Vaccine Branch, Center for Cancer Research, National Cancer Institute, Frederick, MD 21702-1201, USA; margherita.rosati@nih.gov (M.R.); dimitrios.stellas@nih.gov (D.S.); sevasti.karaliota@nih.gov (S.K.); george.pavlakis@nih.gov (G.N.P.)

4 National Hellenic Research Foundation, Institute of Chemical Biology, 11635 Athens, Greece

5 Fourth Department of Internal Medicine, University General Hospital "Attikon", School of Medicine, National and Kapodistrian University of Athens, 11527 Athens, Greece; Ananto@med.uoa.gr (A.A.); grigoropoulou.sotiria@gmail.com (S.G.); tsiodras@med.uoa.gr (S.T.)

6 National Influenza Reference Laboratory of Southern Greece, Hellenic Pasteur Institute, 11521 Athens, Greece; mentis@pasteur.gr (A.M.); vlabropoulou@pasteur.gr (S.L.)

7 Hematology Laboratory-Blood Bank, Aretaieion Hospital, School of Medicine, National and Kapodistrian University of Athens, 11528 Athens, Greece; mariannapolitou@gmail.com

8 First Department of Critical Care Medicine and Pulmonary Services, Evangelismos General Hospital, National and Kapodistrian University of Athens, 11527 Athens, Greece; akotanid@gmail.com (A.K.); ikalom@med.uoa.gr (I.K.); edison.jahaj@gmail.com (E.J.)

9 3rd Department of Internal Medicine, Sotiria General Hospital, School of Medicine, National and Kapodistrian University of Athens, 11527 Athens, Greece; gpoulakou@gmail.com (G.P.); john-tron@hotmail.com (I.T.)

10 Human Retrovirus Pathogenesis Section, Vaccine Branch, Center for Cancer Research, National Cancer Institute, Frederick, MD 21702, USA; xintao.hu@nih.gov (X.H.); jenifer.bear@nih.gov (J.B.); robert.burns@nih.gov (R.B.); barbara.felber@nih.gov (B.K.F.)

11 Basic Science Program, Frederick National Laboratory for Cancer Research, Frederick, MD 21701, USA

12 Haematology-Lymphomas Department and BMT Unit, Evangelismos Hospital, 10676 Athens, Greece; marianpagoni@yahoo.com

13 Transfusion Service and Clinical Hemostasis of Saint Savvas, Oncology Hospital of Athens, 11522 Athens, Greece; egrouzi@otenet.gr

14 Hellenic National Blood Transfusion Center, 13678 Athens, Greece; kostas.stamoulis@gmail.com

* Correspondence: vaspappa@med.uoa.gr; Tel.: +30-210-583-2317

+ Correspondence: G.N.P. and M.A.D. contributed equally to this work as last authors.

Abstract: COVID-19 is a global pandemic associated with increased morbidity and mortality. Convalescent plasma (CP) infusion is a strategy of potential therapeutic benefit. We conducted a multicenter phase II study to evaluate the efficacy and safety of CP in patients with COVID-19, grade 4 or higher. To evaluate the efficacy of $\mathrm{CP}$, a matched propensity score analysis was used comparing the intervention $(n=59)$ to a control group $(n=59)$. Sixty patients received CP within a median time of 7 days from symptom onset. During a median follow-up of 28.5 days, $56 / 60$ patients fully recovered and 1 patient remained in the ICU. The death rate in the CP group was $3.4 \%$ vs. $13.6 \%$ in the control group. By multivariate analysis, CP recipients demonstrated a significantly reduced risk 
of death [HR: 0.04 (95\% CI: 0.004-0.36), p: 0.005], significantly better overall survival by Kaplan-Meir analysis $(p<0.001)$, and increased probability of extubation [OR: 30.3 (95\% CI: 2.64-348.9), $p$ : 0.006]. Higher levels of antibodies in the $\mathrm{CP}$ were independently associated with significantly reduced risk of death. CP infusion was safe with only one grade 3 adverse event (AE), which easily resolved. $\mathrm{CP}$ used early may be a safe and effective treatment for patients with severe COVID-19 (trial number NCT04408209).

Keywords: convalescent plasma; COVID-19; efficacy; SARS-CoV-2 antibodies

\section{Introduction}

The SARS-CoV-2 coronavirus outbreak, which first occurred in Wuhan, China, on 12 December 2019, is now a global threat. The SARS-CoV-2 virus causes a severe form of infection called corona-virus disease 2019 (COVID-19) [1,2]. The SARS-CoV-2 virus is a b coronavirus and has an $84 \%$ nucleic acid homology to the Chinese Horseshoe bat, $78 \%$ similarity with SARS-CoV and 50\% with MERS-CoV [3]. The four structural genes of SARS-CoV-2 encode the nucleocapsid protein $\mathrm{N}$, the spike protein $\mathrm{S}$, the small membrane protein $\mathrm{SM}$, the membrane glycoprotein $\mathrm{N}$ and an additional membrane glycoprotein HE [4].

Similar to other viruses, SARS-CoV-2 infects the pulmonary alveolar epithelial cells by endocytosis using the receptor of the angiotensin II converting enzyme (ACE II) [5].

In $80 \%$ of cases the disease is mild, but in some patients, especially in patients with comorbidities, a severe form of the disease develops, with increased mortality associated with complications such as acute respiratory distress syndrome [6,7] and cardiovascular and thromboembolic events [8-11].

Until now, only three agents have shown some clinical efficacy in large randomized controlled trials, namely remdesivir for hospitalized patients with pulmonary involvement, dexamethasone in hospitalized patients in need of oxygen support and colchicine for moderate to severe disease, reducing the length of oxygen therapy and hospitalization [12-14]. In addition, passive immunization of patients using convalescent plasma (CP) from individuals fully recovered from COVID-19 [15] is a therapeutic strategy with potential benefit. The administration of $\mathrm{CP}$ or hyperimmune globulins (hyper-IG) from patients recovered from other viral infections, i.e., SARS, MERS, Influenza A H1N1 and Ebola virus, has been used in the past, resulting in reduction of the duration of hospitalization and reduction of mortality [16-19]. $\mathrm{CP}$ infusion transfers antibodies against the above-described viral proteins capable of neutralizing the virus; it also exerts immunomodulatory effects like neutralization of cytokines, complements and autoantibodies and may also activate immune cells like dendritic cells as well as T and B-cells [20].

Published data on the use of CP for the treatment of COVID-19 are gradually increasing, with various results depending on the design of the trials and the population of the patients [21-47]. Recently, the FDA modified the Emergency Use Authorization of CP [48] to the use of high titer CP for the treatment of hospitalized patients with COVID-19 early in the disease course and for hospitalized patients with impaired humoral immunity who cannot produce an adequate antibody response [49].

Taking into consideration discrepancies in the literature about the efficacy of CP infusion in severe COVID-19, we conducted a phase II multicenter study aimed at investigating the efficacy of CP for the treatment of hospitalized patients with severe COVID-19, regarding overall survival on day 28 as well as the safety of the treatment and its effect on clinical improvement like duration of hospitalization, of stay in the ICU and of oxygen support. We compared the outcomes to a matched control group of patients treated in the same hospitals during the same time period not receiving the intervention and treated according to the standard of care. 
We present here the outcome of CP infusion on the first 60 patients with COVID-19 treated with CP and compare the results of $59 \mathrm{CP}$ recipients to 59 controls using a matched propensity score analysis.

\section{Materials and Methods}

\subsection{Study Design}

This study is a multicenter ongoing prospective phase II trial (identifier number NCT04408209), conducted at 5 hospitals in Athens, Greece. All study procedures were carried out in accordance with the declaration of Helsinki (18th World Medical Association Assembly), its subsequent amendments, Greek regulations and guidelines, as well as the good clinical practice guidelines (GCP) as defined by the International Conference of Harmonization. The study was also approved by the local ethics committees of all participating hospitals. All patients provided written informed consent.

The primary endpoint was survival on day 28. The secondary endpoints were: time to clinical improvement (i.e. patients not fulfilling the criteria for severe disease), safety, duration of hospitalization, duration of stay in the ICU, duration of ventilation support/ECMO if applicable, and time until negative SARS-CoV-2 PCR (nasal/pharyngeal swab). Additional analyses performed included the predictive value of comorbidities and inflammation markers on mortality, the titer of anti-SARS-CoV-2 antibodies in the infused plasma units, and investigation of the titer of anti-SARS-CoV-2 antibodies in the patients before the infusion of CP on days 1-7 and weekly until day 35.

\subsection{Patients' Inclusion Criteria and Longitudinal Analyses Performed}

From 7 May 2020 to 10 November 2020, 60 patients with $\geq$ grade 4 COVID-19 disease according to $\mathrm{WHO}$ criteria were enrolled in the study and received CP transfusion. The diagnosis was confirmed by real-time RT-PCR assay of the nasopharyngeal swab. Inclusion criteria included: (1) age > 18 years; (2) confirmed COVID-19 by PCR; (3) symptom onset less than 10 days prior; (4) severe disease as shown by one of the following: (i) respiratory rate 30 min; (ii) Hb SAT 93\% (FiO2 = 0.21); (iii) CRP > 1.5 (NR < 0.4) or > 3x UNL; ferritin $>100 \mathrm{ng} / \mathrm{mL}$; (iv) PaO2:FiO2 < $300 \mathrm{mg}$; (v) pulmonary infiltrates on CT scan or chest X-ray; (5) life-threatening disease as determined by one of the following: (i) respiratory failure; (ii) septic shock; (iii) multiorgan failure; (iv) intubation duration < 72 h; (6) signed, informed consent by either the patient or the patient's legal representative in the case of intubated patients.

Patients fulfilling criteria 1, 2, 3, 6 and one of either 4 or 5 were included. The control group included patients hospitalized during the same time period and with similar disease characteristics at the time of admission but who did not sign informed consent to receive CP; these patients were included only so their data could be analyzed. Clinical and laboratory parameters were registered for the first 7 days for the CP recipients only and on a weekly basis thereafter until day 28. Anti-SARS-CoV-2 antibody titers were determined in the recipients only on days $1-7$ and on days 14,21 and 28.

A real-time one-step reverse transcription-PCR, specific for the ORF1ab gene of SARSCoV-2 and for the $\mathrm{N}$ gene of all other coronaviruses, from the nasopharyngeal swab was performed on days $1,4,7,10,14,21$, and 28 in the CP recipients using the VIASURE SARS-CoV-2 Real Time PCR Detection Kit (CerTest Biotec SL, Zaragoza, Spain). The Ct values reflecting the number of cycles needed for the first detection of the viral RNA during the real-time PCR reaction were used as an indirect indication of the viral load (higher $\mathrm{Ct}$ values reflected lower viral load).

\subsection{CP Infusion Treatment Protocol}

All patients received treatment with single-donor $\mathrm{CP}, \mathrm{ABO}$ identical, that included the infusion of 200-233 $\mathrm{mL}$ of CP in 30-60 min on days 1, 3 and 5. The CP stored as fresh frozen plasma, negative for HBV, HCV, HIV, VDRL, and HTLV-1, was infused within $1 \mathrm{~h}$ after thawing. 


\subsection{CP Donors}

Individuals who had recovered from SARS-CoV-2 infection were invited to donate plasma after written informed consent was obtained. Criteria for plasma donors' inclusion were previously described [50].

\subsection{Detection of Anti-SARS-CoV-2 Antibodies in the Donors and Recipients}

We used two methods for the detection of anti-SARS-CoV-2 antibodies in putative plasma donors, as previously described [50]. The main method used for making the decision to proceed to plasmapheresis was a commercially available ELISA (Euroimmun Medizinische Labordiagnostika AG) that detects IgG and IgA antibodies against the recombinant S1 domain of the Spike protein of the virus (S1 domain), as previously described [50]. The results were interpreted as positive if the index value was $>1.1$ optical density (OD), negative if $<0.9 \mathrm{OD}$, and borderline between 0.8 and $1.1 \mathrm{OD}$. This method was also used for the detection of anti-SARS-CoV-2 antibodies in the plasma recipients during the course of the disease.

In both donors and recipients, we also performed (i) an in-house ELISA to detect either the complete Spike (amino acid (AA) 15-1208_2P) or Spike-RNA binding domain (Spike_RBD) (AA 319-525) using mammalian Expi293-cell-produced proteins, or E. coliproduced complete Nucleocapsid protein $(\mathrm{N})$ or its RNA binding domain (N-RBD, AA 47173 ) and (ii) a neutralizing antibody (NAb) assay using SARS-CoV-2 pseudotyped virus, as previously described $[50,51]$.

\subsection{Statistical Analysis}

A matched propensity score analysis was performed to select the most suitable controls for the intervention group. A 1:1 ratio without replacement was used. The factors selected for matching were age, gender, baseline SOFA score, time from symptom onset to diagnosis, and concomitant dexamethasone use. A standardized difference below 0.3 after the matching process was considered acceptable. After matching, the baseline characteristics of the control group were compared to the intervention group using non-parametric tests, as appropriate. For reasons of comparability, day 1 was defined as the day of hospital admission, for both the intervention and the control group for all parameters analyzed, except for the longitudinal analyses performed in the CP group, where day 1 was defined as the first day of $\mathrm{CP}$ infusion.

Univariate Cox proportional hazard regression models were used to evaluate timedependent outcomes, namely time to death, time to exit from ICU, time to intubation and extubation, time to hospital discharge, and time to achievement of SARS-CoV-2 PCR negativity. Regarding overall survival, variables that were found to be statistically significant in the univariate analysis were included in a multivariate Cox regression model. A subgroup analysis regarding the primary endpoint by the level of antibodies in the infused CP was also performed. Univariate binary logistic regression was used to assess the aforementioned outcome irrespective of time. Kaplan-Meier analysis was used to evaluate cumulative incidence as a function of time. The log-rank Mantel-Cox test was used to test for statistically significant differences of survival. Clinical status on day 14, 28 and at the end of follow-up was evaluated with univariate ordinal logistic regression analysis. The respective variable consisted of four categories, namely death, hospitalized in ICU, hospitalized, and discharged from hospital.

All continuous variables including antibody levels were summarized as median and interquartile range (IQR), assuming deviation from normality. Categorical variables were constructed using the median as cut-off. Antibody levels among different subgroups were compared using Kruskal-Wallis test and Mann-Whitney-Wilcoxon tests. Univariate and multivariate binary logistic regression analyses with the antibody levels as a dependent variable were used to find predictors of antibody response in donors and recipients.

Laboratory variables, including lymphocytes, platelets, C-reactive protein (CRP), ferritin, fibrinogen, LDH, IL-6, SARS-CoV-2 Ct values, SOFA score as previously de- 
scribed [52], and antibody levels on days 2, 7, 14, 21 and 28 were compared to the respective variables on day 1 using non-parametric Wilcoxon test for related samples. For these variables, day 1 was defined as the day of first $C P$ infusion, and all measurements on day 1 were conducted prior to the $\mathrm{CP}$ infusion. The trend of clinical and laboratory variables as well as antibody levels over time were evaluated fitting a generalized linear model using generalized estimating equations. Assuming an asymmetrical distribution of variables, logarithmic transformation was performed. The effect of the antibody levels in the infused plasma on the trend of each variable was evaluated incorporating an antibody*time interaction term in the respective model.

All statistical analyses were performed using SPSS version 23. Matched propensity score analysis was performed using SAS.

\section{Results}

\subsection{CP Donors}

60 units of $\mathrm{CP}$ were collected by plasmapheresis from 59 patients (36 males and 23 female); one patient had undergone two consecutive plasmapheresis sessions, as she was found to have high antibodies during follow-up. Median age was 46 years (IQR: 22), and median time from symptom onset to plasmapheresis was 61.5 days. All donors were positive for anti-SARS CoV-2 antibodies on the day of plasmapheresis; median level of antiS1 IgA was 6.13 (IQR: 5.35) and median level of IgG antibodies was 3.42 (IQR: 5.37), using the Euroimmun ELISA. The respective medians for antibodies according to the in-house ELISA were Spike 4.77 (IQR: 2.07), Spike_RBD 3.96 (IQR: 2.40), N_RBD 2.94 (IQR: 2.51), and Neutralizing Abs ID50 2.48 (IQR: 1.49).

\subsection{CP Recipients: Clinical Characteristics}

From 7 May 2020 to 10 November 2020, 60 patients with WHO grade $\geq 4$ COVID-19 disease were enrolled and received CP transfusion. A 67-year-old male with multiple myeloma, who received one dose of $\mathrm{CP}$ following intubation and succumbed to the infection the following day was excluded from the comparative analyses because a matched control patient could not be found. Patient characteristics at diagnosis are shown in Table 1. Median age was 59 years (IQR: 18 years). Median time from symptom onset to hospital admission and CP transfusion was three days and seven days, respectively. Antibacterial treatment and dexamethasone were used in $59.3 \%$ of the patients, whereas remdesivir and hydroxychloroquine were used in $5.1 \%$ and $3.4 \%$ of the patients, respectively. 
Table 1. Comparison of baseline characteristics of patients in the convalescent plasma and the control group.

\begin{tabular}{|c|c|c|c|}
\hline & Convalescent Plasma Group $(n=59)$ & Control Group $(n=59)$ & $p$-Value \\
\hline $\begin{array}{c}\text { Age, median (IQR) } \\
<60 \text { years } \% \\
>60 \text { years } \%\end{array}$ & $\begin{array}{c}59(18.0) \\
45.8 \\
55.2\end{array}$ & $\begin{array}{l}59(20) \\
50.8 \\
492\end{array}$ & 0.893 \\
\hline$\geq 60$ years $\%$ & & & \\
\hline Gender, \% & & & 0.564 \\
\hline Female & 32.2 & 37.3 & \\
\hline Male & 67.8 & 62.7 & \\
\hline Comorbidities, \% & 61.0 & 62.7 & 0.393 \\
\hline Diabetes & 19.3 & 28.3 & 0.269 \\
\hline Arterial hypertension & 29.8 & 37.7 & 0.382 \\
\hline Coronary artery disease & 7.0 & 13.2 & 0.282 \\
\hline Pulmonary disease & 14.0 & 9.4 & 0.457 \\
\hline Renal impairment & 8.8 & 11.3 & 0.276 \\
\hline Solid tumor & 1.8 & 7.5 & 0.658 \\
\hline Hematological malignancy & 3.5 & 1.9 & 0.603 \\
\hline \multicolumn{4}{|l|}{ Symptoms, $\%$} \\
\hline Fever & 98.2 & 96.6 & 0.571 \\
\hline Myalgia & 8.8 & 10.3 & 0.775 \\
\hline Cough & 56.1 & 48.3 & 0.401 \\
\hline Dyspnea & 36.8 & 53.4 & 0.08 \\
\hline Loss of taste & 8.8 & 3.4 & 0.235 \\
\hline Anosmia & 5.3 & 5.2 & 0.983 \\
\hline Diarrhea & 19.3 & 19.0 & 0.964 \\
\hline $\begin{array}{l}\text { Lymphocytes, (109/L, NR: } 1.1-4.0) \\
\text { Ly }\end{array}$ & $1.17(0.7)$ & $1.02(0.6)$ & 0.207 \\
\hline Platelets, (109/L, NR: 130-400) & $196(101.5)$ & 197 (75.3) & 0.721 \\
\hline CRP, (mg/L, NR: $0.00-6.00)$ & $47(50.3)$ & $44.8(71.9)$ & 0.772 \\
\hline Fibrinogen, (mg/dL, NR: 200-400) & 485 (173) & $477(253.9)$ & 0.631 \\
\hline LDH, (U/L, NR: 135-225) & $315(167.8)$ & 277 (127.3) & 0.165 \\
\hline Ferritin, (ng/mL, NR: 13-150) & $597(451.5)$ & $474(167.9)$ & 0.443 \\
\hline Intereukin- $6,(\mathrm{pg} / \mathrm{mL}, \mathrm{NR}:<7)$ & $30.5(43.6)$ & & \\
\hline SARS-CoV-2 PCR CT value & $26.8(6.9)$ & $27.5(9.3)$ & 0.700 \\
\hline Percentage of infiltrates at baseline $\mathrm{CT}, \%$ & & & 0.117 \\
\hline$<25$ & 29.1 & 39.6 & \\
\hline $25-50$ & 38.2 & 43.8 & \\
\hline $50-75$ & 25.5 & 8.3 & \\
\hline$\geq 75 \%$ & 7.3 & 8.3 & \\
\hline Concomitant dexamethasone, $\%$ & 59.3 & 49.2 & 0.270 \\
\hline Baseline SOFA score & $5(4)$ & $4(4)$ & 0.295 \\
\hline Time from first symptom to diagnosis, median (IQR) & $3(4]$ & $4(3)$ & 0.265 \\
\hline Time from first symptom to CP infusion, median (IQR) & $7(4)$ & & \\
\hline Time from diagnosis to $\mathrm{CP}$ infusion, median (IQR) & $3(3)$ & & \\
\hline
\end{tabular}


Regarding oxygen support, $15 \%$ of the patients were on room air, $43.3 \%$ were on nasal cannula, $31.7 \%$ on venturi mask and $10 \%$ on mechanical ventilation.

On computer-assisted tomography $(\mathrm{CT})$, all patients showed bilateral ground-glass opacities and/or pulmonary parenchymal consolidation with predominantly subpleural and bronchovascular bundle distribution. The percentage of infiltrates in the baseline CT scan is shown in Table 1.

\subsection{Control Group}

Records of all patients who were diagnosed during the same time period and hospitalized in the same tertiary hospitals as the CP recipients were retrospectively obtained. Thus, 144 controls were included in the matched propensity score analysis. Matching according to age, gender, baseline SOFA score, time from symptom onset to diagnosis, and concomitant use of dexamethasone resulted in the exclusion of 85 controls. The remaining 59 controls were included in the final analysis. As shown in Table 1, comparison of baseline characteristics and concomitant medication between the intervention and control groups yielded no statistically significant differences.

\subsection{Outcomes}

Regarding primary outcome after a median follow-up of 28.5 days, comparing the $59 \mathrm{CP}$ recipients to the control group, 57/59 recipients $(98.3 \%)$ remained alive. Fifty-six patients recovered completely and were discharged from hospital after a median length of hospital stay of 15 days, whereas one patient remained intubated in the ICU. Regarding the two deaths in the CP group (3.4\%), these included an 82-year-old female with a history of dementia and hypertension who was intubated on day 2 after CP infusion and died of bacterial sepsis after 20 days and a 69-year-old male with a history of hypertension who was intubated on day 2 following CP infusion and died of bacterial sepsis after 66 days.

Regarding the control group, 51/59 (86.4\%) patients were discharged after a median hospital stay of 10 days, whereas eight patients (13.6\%) died within a median follow-up of 12 days, as shown in Table 2. Sixteen patients of the intervention group were intubated and 13 of them were extubated and discharged from ICU after a median of 15 days. It should be noted that four patients were intubated prior to the CP infusion. Eight controls were intubated; among them, one was extubated and exited the ICU. Comparison of outcomes between the intervention and the control group are summarized in Table 2. Patients in the intervention group had a significantly longer median follow-up time of 29 days vs. 10 days and a longer duration of hospitalization of 15 days vs. 10 days in the control group.

Univariate analysis of factors associated with the primary endpoint demonstrated a statistically significant association between CP and overall survival (OS) (HR: 0.05, 95\% CI: 0.01-0.43), as shown in Table 3. The Kaplan-Meier analysis, depicted in Figure 1, also showed a statistically significant association between CP infusion and better OS (Logrank $p<0.001$ ). In a subgroup analysis by the level of antibodies in the infused plasma, no differential effect of antibody levels was found on OS (Table 3). Factors associated with reduced OS were advanced age (HR: 1.08 (95\% CI: 1.01-1.14), $p$ : 0.024) and the percentage of infiltrates in the CT scan (HR: 2.53 (95\% CI: 1.24-5.19), p: 0.011), as shown in Table 3. A multivariate model incorporating statistically significant factors, obtained by the univariate analysis, including age and percentage of CT infiltrates and CP infusion, confirmed the independent significant association of CP infusion with better overall survival, as shown in Table 4. Interestingly, on multivariate analysis, infusion of CP with high (above the median) Spike, Spike RBD, N_RBD antibodies or ID50 was associated with improved OS, as opposed to infusion of CP with low antibody levels, where no significant association was noted. 
Table 2. Comparison of outcomes of patients in the convalescent plasma and the control group.

\begin{tabular}{|c|c|c|c|}
\hline & Convalescent Plasma Group $(n=59)$ & Control Group $(n=59)$ & $p$-Value ${ }^{1}$ \\
\hline Status at day 14 & $n(\%)$ & $n(\%)$ & 0.249 \\
\hline Discharged & $21(35.6)$ & $31(52.5)$ & \\
\hline Hospitalized & $30(50.8)$ & $18(30.5)$ & \\
\hline Death & $0(0.0)$ & $5(8.5)$ & \\
\hline Status at day 28 & $n(\%)$ & $n(\%)$ & 0.566 \\
\hline Discharged & $48(81.4)$ & $46(78.0)$ & \\
\hline Hospitalized & $5(8.5)$ & $5(8.5)$ & \\
\hline In ICU & $5(8.5)$ & $3(5.1)$ & \\
\hline Death & $1(1.7)$ & $5(8.5)$ & \\
\hline Status at end of follow-up & $n(\%)$ & $n(\%)$ & 0.106 \\
\hline Discharged & $56(94.9$ & $51(86.4)$ & \\
\hline Hospitalized & $0(0.0)$ & $0(0.0)$ & \\
\hline In ICU & $1(1.7)$ & $0(0.0)$ & \\
\hline Death & $2(3.4)$ & $8(13.6)$ & \\
\hline Follow-up, median (IQR) & $29(24)$ & $10(11)$ & $<0.001$ \\
\hline Duration of hospital stay, median (IQR) & $15(10)$ & $10(11)$ & 0.006 \\
\hline Exit from ICU, $n(\%)$ & $13(22.0)$ & $2(3.4)$ & 0.014 \\
\hline Time to exit from ICU, median (IQR) & $12.5(37.25)$ & $7(\mathrm{NC})$ & 0.824 \\
\hline Intubation, $n(\%)$ & $16(27.1)$ & $8(13.6)$ & 0.068 \\
\hline Extubation, $n(\%)$ & $13(22.0)$ & $1(1.7)$ & 0.006 \\
\hline Time to extubation, median (IQR) & $15(35.5)$ & $17.5(\mathrm{NC})$ & 0.837 \\
\hline Duration of oxygen support, median (IQR) & $7(11.5)$ & NA & \\
\hline Achievement of negative PCR, $n(\%)$ & $37(62.7)$ & $19(52.8)$ & 0.167 \\
\hline Time to PCR negativity, median (IQR) & $14(14)$ & $9.5(14.8)$ & 0.007 \\
\hline
\end{tabular}

${ }^{1}$ Highlighted (bold) $p$-values denote statistically significant results. 


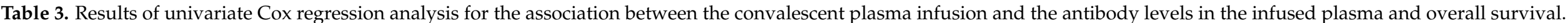

\begin{tabular}{|c|c|c|}
\hline Variables $^{2}$ & HR $(95 \% \mathrm{CI})$ & $p$-Value ${ }^{1}$ \\
\hline Age & $1.08(1.01-1.14)$ & 0.024 \\
\hline Male gender & $1.22(0.34-4.35)$ & 0.761 \\
\hline Percentage of infiltrates at CT & $2.53(1.24-5.19)$ & 0.011 \\
\hline Dexamethasone co-medication & $1.43(0.39-5.19)$ & 0.586 \\
\hline Convalescent plasma infusion & $0.05(0.01-0.43)$ & 0.006 \\
\hline N_RBD (In-house ELISA), below median & $0.07(0.007-0.76)$ & 0.029 \\
\hline N_RBD (In-house ELISA), above median & $0.04(0.002-0.62)$ & 0.021 \\
\hline Spike (In-house ELISA), above median & $0.04(0.002-0.61)$ & 0.012 \\
\hline Spike_RBD (In-house ELISA), below median & $0.07(0.006-0.74)$ & 0.027 \\
\hline Spike_RBD (In-house ELISA), above median & $0.04(0.002-0.58)$ & 0.019 \\
\hline ID50, below median & $0.08(0.007-0.88)$ & 0.039 \\
\hline ID50, above median & $0.04(0.003-0.55)$ & 0.016 \\
\hline
\end{tabular}

${ }^{1}$ Highlighted (bold) $p$-values denote statistically significant results; ${ }^{2}$ Reference category: no plasma infusion. 


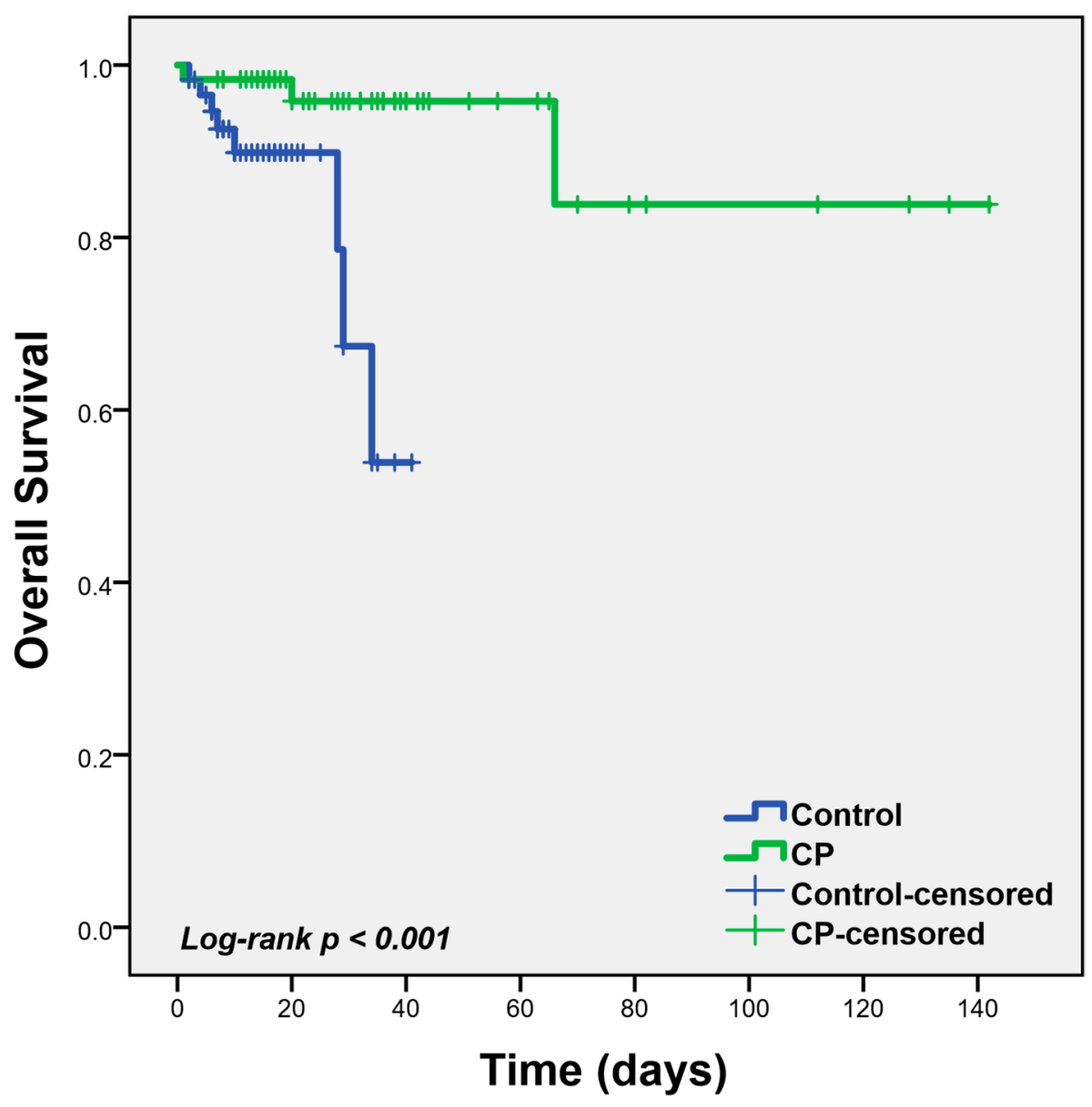

Figure 1. Kaplan-Meier Survival analysis of the recipients and controls.

Table 4. Results of multivariate Cox regression analysis for the association between the convalescent plasma infusion and the antibody levels in the infused plasma and overall survival.

\begin{tabular}{ccc}
\hline Variables & HR (95\%CI) & $p$-Value ${ }^{\mathbf{1}}$ \\
\hline Age & $1.04(0.97-1.12)$ & 0.233 \\
Percentage of infiltrates at CT & $3.87(1.56-9.58)$ & $\mathbf{0 . 0 0 3}$ \\
Convalescent plasma infusion & $0.04(0.004-0.36)$ & $\mathbf{0 . 0 0 5}$ \\
\hline Subgroup analyses by level of plasma & & \\
antibodies (cut -off: median) ${ }^{2}$ & & \\
N_RBD (In-house ELISA), below median & $0.08(0.006-1.09)$ & 0.059 \\
N_RBD (In-house ELISA), above median & $0.02(0.001-0.34)$ & $\mathbf{0 . 0 0 7}$ \\
Spike (In-house ELISA), below median & $0.10(0.008-1.21)$ & 0.070 \\
Spike (In-house ELISA), above median & $0.02(0.001-0.33)$ & $\mathbf{0 . 0 0 7}$ \\
Spike_RBD (In-house ELISA), below median & $0.08(0.007-1.003)$ & 0.051 \\
Spike_RBD (In-house ELISA), above median & $0.02(0.001-0.35)$ & $\mathbf{0 . 0 0 8}$ \\
\hline ID50, below median & $0.14(0.01-1.91)$ & 0.139 \\
ID50, above median & $0.02(0.001-0.29)$ & $\mathbf{0 . 0 1 6}$
\end{tabular}

${ }^{1}$ Highlighted (bold) $p$-values denote statistically significant results; ${ }^{2}$ Reference category: no plasma infusion.

Regarding the association of $\mathrm{CP}$ infusion with secondary outcomes, the results of univariate analysis are presented in Table 5 . No association was found between $\mathrm{CP}$ infusion and clinical status on days 14 and 28 as well as at the end of follow-up. CP infusion was not associated with the risk of intubation or admission to ICU. Finally, CP infusion was not associated with time to reach SARS-CoV-2 PCR negativity. However, a statistically significant association between $\mathrm{CP}$ infusion and extubation or exit from ICU was noted 
(OR: 30.3, 95\% CI: 2.64-348.9, OR: 15.16, 95\% CI: 2.02-113.3, respectively). High antibody titers in the infused $\mathrm{CP}$ predicted a significantly higher rate of extubation and exit from ICU (data not shown). In addition, as shown in Supplementary Table S1, advanced age and percentage of infiltrates in the CT scan were associated with worse clinical outcome at the end of follow-up (OR: 1.07 (95\% CI: 1.01-1.13), p: 0.018 and OR: 2.41 (95\% CI: 1.19-4.85), $p: 0.014$, respectively). Factors associated with increased risk for intubation were advanced age (OR: 1.05 (95\% CI: 1.01-1.10), $p: 0.013)$, percentage of infiltrates in the CT scan (OR: 2.57 (95\% CI: 1.47-4.49), p: 0.001) and advanced SOFA score [OR: 1.48 (95\% CI: 1.19-1.84), $p: 0.001)$, as shown in Supplementary Table S1.

Table 5. Results of univariate regression analyses for the association between the convalescent plasma infusion and secondary outcomes.

\begin{tabular}{ccc}
\hline Variables & Effect Estimate (95\%CI) & $p$-Value ${ }^{\#}$ \\
\hline Clinical status at day 14 & OR: $1.50(0.76-2.98)$ & $0.244^{1}$ \\
\hline Clinical status at day 28 & OR: $0.77(0.31-1.88)$ & $0.565^{1}$ \\
\hline Clinical status at end of follow-up & OR: $0.33(0.08-1.33)$ & $0.119^{1}$ \\
\hline Hospital discharge & OR: $2.93(0.74-11.64)$ & $0.127^{2}$ \\
Time to hospital discharge & HR: $0.68(0.46-0.99)$ & $\mathbf{0 . 0 5}^{3}$ \\
\hline Intubation & OR: $2.37(0.93-6.01)$ & $0.072^{2}$ \\
Time to intubation & HR: $0.48(0.19-1.21)$ & $0.122^{3}$ \\
\hline Extubation & OR: $30.3(2.64-348.9)$ & $\mathbf{0 . 0 0 6 ^ { 2 }}$ \\
Time to extubation & HR: $0.68(0.08-5.44)$ & $0.712^{3}$ \\
\hline Exit from ICU & OR: $15.16(2.02-113.3)$ & $\mathbf{0 . 0 0 8}{ }^{\mathbf{2}}$ \\
Time to exit from ICU & HR: $0.54(0.07-4.41)$ & $0.566^{3}$ \\
\hline Achievement of PCR negativity & OR: $1.84(0.78-4.36)$ & $0.168^{2}$ \\
Time to reach PCR negativity & HR: $0.74(0.42-1.29)$ & $0.741^{3}$ \\
\hline
\end{tabular}

${ }^{\#}$ Highlighted (bold) $p$-values denote statistically significant results ${ }^{1}$ Ordinal logistic regression analysis; ${ }^{2}$ binary logistic regression analysis; ${ }^{3}$ cox proportional hazard regression analysis.

Subgroup analysis by stratifying recipients according to the time of $\mathrm{CP}$ infusion from symptom onset demonstrated no association with any secondary outcome. Sensitivity analysis after the exclusion of patients intubated at enrollment did not change the results. Similarly, sensitivity analyses excluding recipients that received CP after four or seven days did not yield different results. No correlation was found between comorbidities and length of hospital or ICU stay or between the pre-treatment levels of anti-SARS-CoV2 antibodies and disease severity (data not shown).

\subsection{Adverse Events}

One patient had a grade 3 adverse event (AE) consisting of severe exacerbation of dyspnea and hypoxemia after infusion of the first $\mathrm{CP}$ dose. The symptoms resolved by conventional measures, and the patient was discharged fully recovered from hospital; however, no subsequent doses of $\mathrm{CP}$ on days 3 and 5 were given. All other AEs were grade 1 , comprising mild erythema in one patient, mild dizziness in one patient, and increased temperature two hours after first $\mathrm{CP}$ infusion in one patient. These AEs were easily handled, and the patients continued the subsequent infusions uneventfully.

\subsection{Longitudinal Analysis of Clinical and Laboratory Parameters in the CP Group}

As shown in Supplementary Figure S1, median SOFA score declined significantly from five to two on day 7 after $\mathrm{CP}$ infusion; however, a slight yet statistically significant decrease was seen even on day 2 from $\mathrm{CP}$ infusion. The generalized linear model predicted an average decrease of $25 \%$ per week ( $p$ : 0.02). No interaction was found between the trend of SOFA score change and the level of antibodies in the infused plasma. 
The changes of laboratory parameters in the $\mathrm{CP}$ recipients, namely lymphocyte and platelet counts as well as CRP, Ferritin, Fibrinogen, LDH and IL-6, are depicted in Supplementary Figure S1.

Among them, CRP, LDH, and fibrinogen decreased significantly on day 7, whereas a delayed decline in ferritin and IL-6 was observed (on days 14 and 21, respectively). No interaction was found between the level of antibodies in the infused plasma and the trend of inflammatory markers over time; however, high titer of neutralizing antibodies predicted a steeper significant decrease of $17.3 \%$ of ferritin $(p<0.001)$ (data not shown).

In addition, regarding viral load, SARS CoV-2 PCR Ct values increased significantly on day 7 (33.1 vs. 26.8, $p<0.01$ ) (Supplementary Figure S1). The generalized linear model predicted an average increase of Ct values by 10\% $(p<0.001)$, unaffected by the levels of antibodies in the infused plasma.

Regarding the anti-SARS-CoV-2 antibodies in the recipients, as shown in Figure 2a, a significant increase of anti-S1 IgG and IgA antibodies was observed, starting on day 2 following CP infusion. IgG anti-S1 increased significantly until day 21, and IgA anti-S1 until day 14. As shown in Figure 2b,c, anti-Nucleocapsid, anti-Nucleocapsid_RBD, anti-Spike, anti-Spike_RBD, and Nab peak levels were observed 1-2 weeks post CP, corresponding to 2-3 weeks post symptom onset. The increase of Nab matched the Spike and Spike_RBD antibody increases. No association was found between the level of donor antibodies and antibody trend in the recipients over time by all methods of detection.
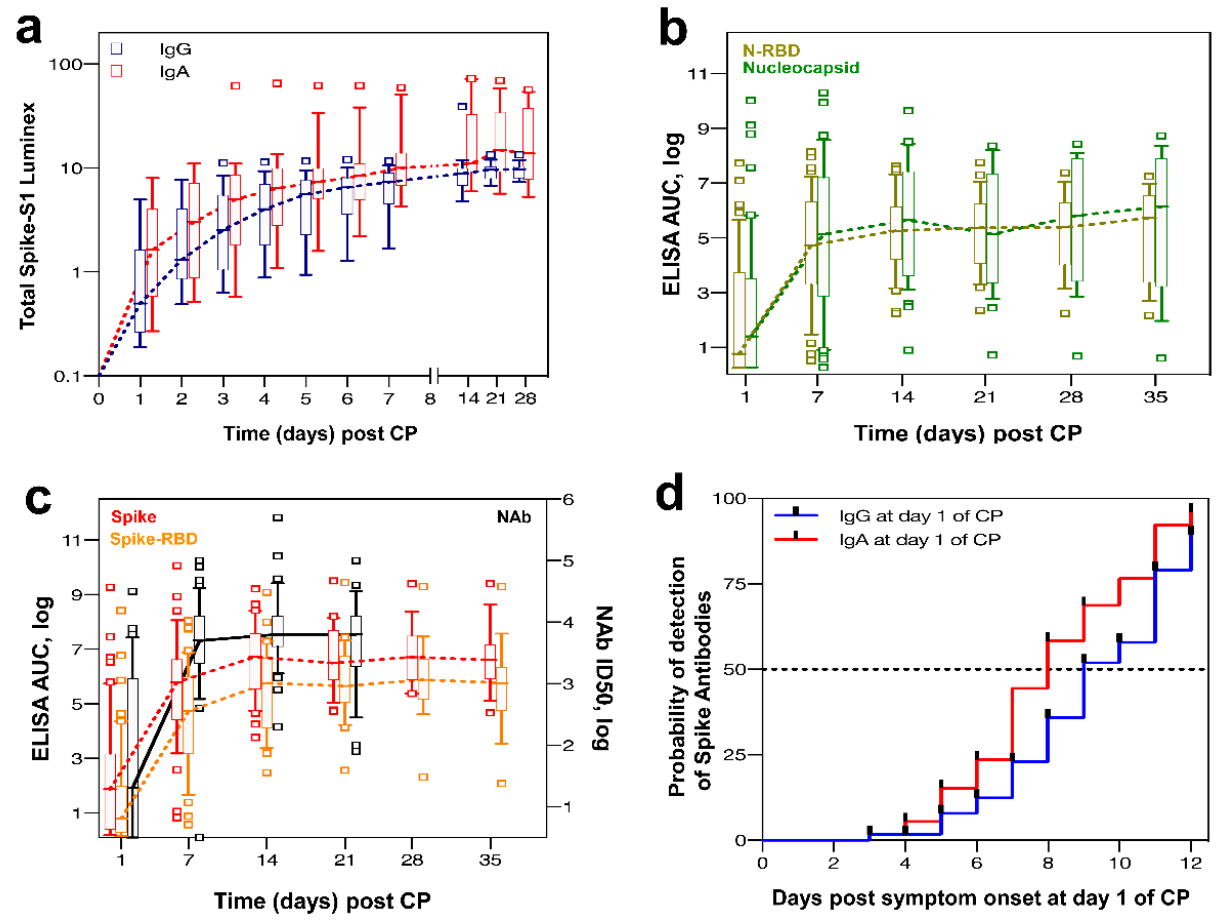

Figure 2. (a) Trend of anti-S1 IgG and IgA antibody levels in the recipients following CP infusion. (b) Trends of Nucleocapsid and N_RBD in the recipients following CP Infusion. (c) Trend of Spike, Spike_RBD and Nab in the recipients following CP infusion. (d) Probability of detection of anti-S1 $\mathrm{IgG}$ and $\mathrm{IgA}$ in the recipients at day 1 of $\mathrm{CP}$ infusion post symptom onset.

\subsection{Subgroup Analysis by the Level of Antibodies at Baseline}

Using the Euroimmun assay at baseline, $31 \%$ of patients were positive for anti-S1 IgG antibodies compared to $62.1 \%$ positive for anti-S1 IgA (Figure 2a). The probability of detection of positive antibodies at baseline was significantly associated with longer symptom duration, as depicted in Figure 2d. No significant differences of clinical characteristics were observed between patients with and without anti-SARS-CoV-2 antibodies at baseline (data not shown). 
Regarding the results of the in-house ELISA at baseline, 26 patients (49\%) from the cohort of 53 patients showed no or very low Spike antibody responses (Figure 2c). Seven patients $(13 \%)$ scored negative for both Spike and Nucleocapsid antibodies.

In subgroup analyses, comparing characteristics and outcomes of patients based on their baseline antibody status by the in-house ELISA assay, positive baseline antibodies were associated with improved clinical outcomes but not with survival. In detail, the presence of Nucleocapsid antibodies at baseline was predictive of improved clinical status on day 7, 14, and 28 (OR: $0.20,95 \%$ CI: $0.05-0.77$, OR: 0.21 , 95\% CI: $0.06-0.71$, and OR: $0.20,95 \%$ CI: 0.04-0.92, respectively). Similarly, the presence of Spike antibodies at baseline was predictive of improved clinical status on day 7, 14, 28 (OR: 0.18, 95\% CI: 0.05-0.71, OR: $0.13,95 \%$ CI: $0.04-0.47$, and OR: $0.18,95 \%$ CI: 0.04-0.76, respectively). Finally, positive Spike-RBD antibodies at baseline were predictive of improved clinical status on days 7 and 14 (OR: 0.25, 95\% CI: 0.06-0.95 and OR: 0.24, 95\% CI: 0.07-0.83, respectively).

Moreover, the presence of positive Spike antibodies by the in-house ELISA at baseline was predictive of a decreased risk or intubation and admission to ICU (OR: $0.22,95 \%$ CI: 0.06-0.88, and OR: $0.22,95 \%$ CI: $0.06-0.88)$, respectively.

Importantly, patients with negative baseline anti-S1-IgG experienced a significantly steeper increase of IgG antibodies between days $1-7$ by $22 \%(p<0.001)$; similarly, patients without baseline anti-S1-IgA demonstrated a steeper increase of $\operatorname{IgA}$, by $19 \%(p<0.001)$, as shown in Figure 3a,b. In addition, patients with negative baseline antibodies for Nucleocapsid, Nucleocapsid_RBD, Spike_RBD, Spike, and Nabs ID50 demonstrated a steeper increase of these antibodies following CP infusion (Figure $3 \mathrm{c}-\mathrm{g}$ ).
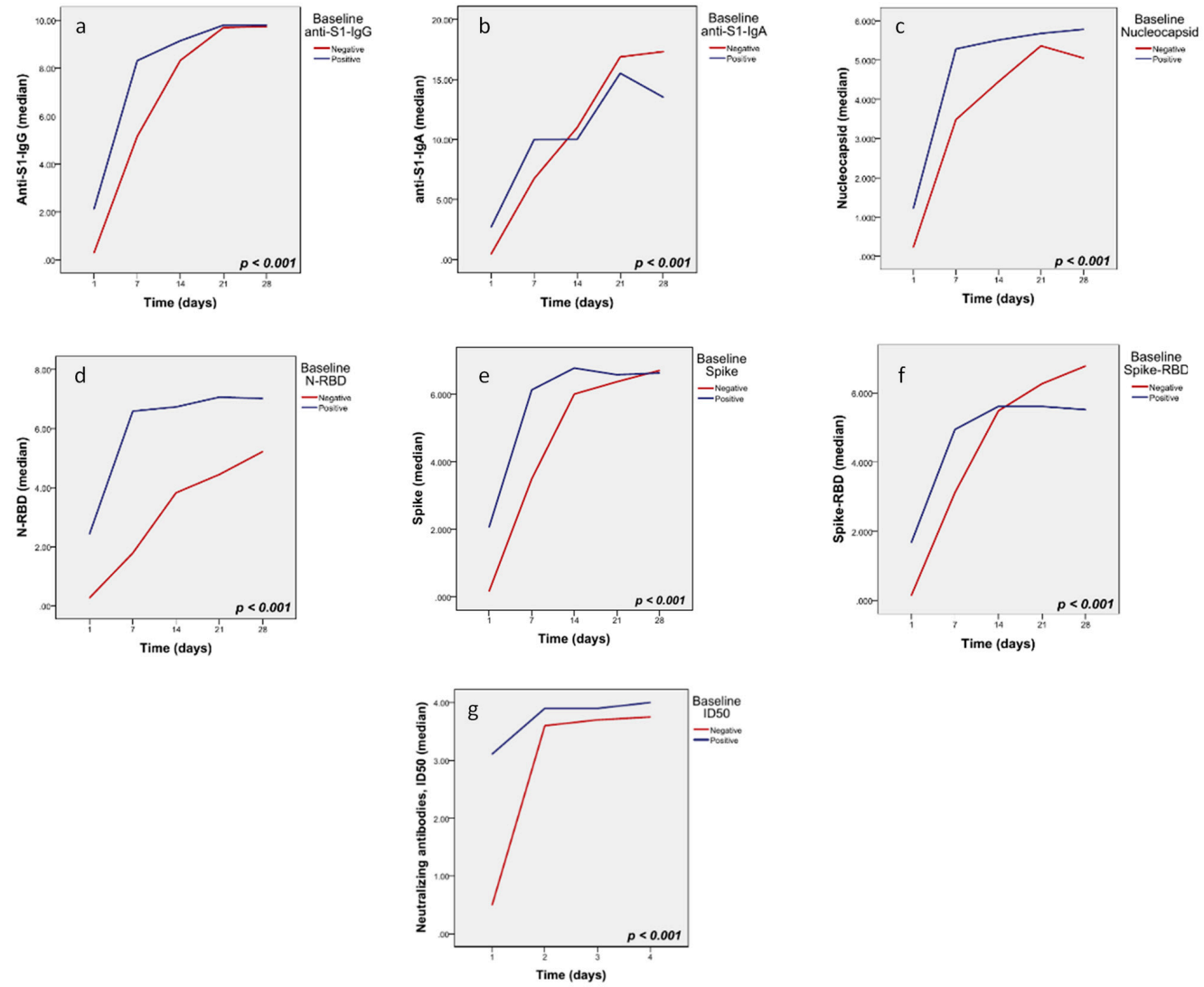

Figure 3. Trend of antibodies by baseline antibody level: (a) anti-S1 IgG, (b) anti-S1-IgA, (c) Nucleocapsid, (d) N_RBD, (e) Spike, (f) Spike_RBD, (g) neutralizing antibodies (ID50).

\section{Discussion}

In this report, we present the results of a multicenter phase II study (NCT04408209) from five participating hospitals in Athens, Greece, on the safety and efficacy of CP in 
60 patients with at least grade 4 COVID-19 and compare the primary and secondary outcomes to a control group of patients using a matched propensity score analysis.

Regarding the dose of $\mathrm{CP}$ and titer of antiviral antibodies in the $\mathrm{CP}$, we did not use any cut-off value, since at the time of designing this study, no data were available regarding this issue. In most clinical trials, one to two units from one or different donors have been proposed for treatment. In some studies, only $\mathrm{CP}$ with arbitrarily defined high titers were used, resulting in significant reduction in the risk of death or disease progression $[28,29,43]$. In the recently published retrospective study based on a US national registry of 3082 patients, the titer of antibodies in CP correlated with clinical outcome, as shown by a reduction of the risk of death within 30 days following high titer $\mathrm{CP}$ infusion, but only for non-intubated patients; this shows the efficacy of this regimen early in the disease course [53]. Recently, guidelines for the selection of high titer CP for COVID-19 according to the level of anti-SARS-CoV-2 antibodies based on different assays were issued by the FDA [49]. Importantly, in our study the median level of IgG anti-S1 antibodies in the CP by the Euroimmun assay was 3.42, which is quite close to the value of 3.5 characterizing the high titer CP determined by the Euroimmun Assay according to the FDA guidelines [49].

Another important issue is the optimal time of $\mathrm{CP}$ infusion following symptom onset. Indeed, early reports have shown that the administration of CP in critically ill COVID-19 patients showed no significant reduction of mortality [54]. Most importantly, Joyner et al. demonstrated that the 7- and the 30-day mortality rates were significantly increased in patients receiving $\mathrm{CP}>4$ days from symptom onset [27]. Generally, the time of $\mathrm{CP}$ infusion differs significantly in the design of different trials, from 10-22 days [25,33,34,40,44-46]. In the study by Altuntas et al., a higher rate of mechanical ventilation support was observed in patients receiving CP 20 days after diagnosis compared to three interval groups $(<5$, 6-10, and 11-15 days, $p=0.001$ ) [23]. We failed to find a significant effect of the time to CP infusion, regarding all primary and secondary outcomes, in accordance with a recently published randomized trial where no significant difference was observed in mortality or disease deterioration in early ( $<7$ days of symptom onset) vs. late CP administration [43].

The data regarding the efficacy of CP in COVID-19 are gradually increasing, including small case series [25,34,36], observational studies [27,32,33,42,55], matched controlled studies $[21,23,30,37-41,44-47,56]$ and a few randomized controlled trials $[22,24,26,28,29,35$, 43], with no definite conclusions. In the observational study by Salazar et al. of 25 patients with severe and life threatening disease, the infusion of $\mathrm{CP}$ resulted in the improvement of disease severity in $76 \%$ of patients [33]. A single arm multicenter trial from Italy using hyperimmune plasma with neutralizing antibodies titer $\geq 1: 160$ also showed a mortality rate $6.5 \%$ lower than an expected $15 \%$ mortality rate according to national statistics [55].

In our study, we examined the beneficial effect of $\mathrm{CP}$ in patients with severe COVID-19 using a matched propensity score analysis. This strategy has already been used in other trials, resulting in contradictory results $[21,23,30,37-41,44-47,56]$. In our study, the univariate analysis comparing the $\mathrm{CP}$ to the control group showed a significantly reduced risk of death. Moreover, the Kaplan-Meir survival analysis revealed a significant difference in OS in favor of the $\mathrm{CP}$ group. Importantly, multivariate analysis confirmed that $\mathrm{CP}$ infusion was associated with a significantly reduced risk of death. The beneficial effect of $\mathrm{CP}$ infusion on survival demonstrated in our study is in accordance with other studies of similar design showing a survival advantage in CP recipients compared to a control group [37,40,41,44]. Some other studies using comparison to a control group have also shown beneficial results in favor of $\mathrm{CP}$ for specific subpopulations, including a survival advantage for non-intubated patients [30], a reduction of disease severity for patients with ARDS [39], and a reduction of mortality for elderly—particularly female - patients admitted to ICU and with comorbidities [38]. On the contrary, other studies did not confirm these beneficial findings when comparing the intervention to a control group [45-47]. However, in one study, $86 \%$ of the patients were intubated and $70 \%$ had already high titers of anti-SARS-CoV-2 antibodies before infusion [45]. In other trials, anti-SARS-CoV-2 antibodies were not determined in the $\mathrm{CP}$, which may have interacted 
with the negative results [46,47]. In one study, the $\mathrm{CP}$ was administered within 21 days after symptom onset [46].

Moreover, our findings have not been confirmed by randomized controlled trials $[22,26,28,35]$. However, several points need to be addressed. The trial published by $\mathrm{Li}$ et al. [28] was prematurely closed after approximately $50 \%$ of planned patient enrollment, possibly rendering the study underpowered to detect any significant differences between the CP and control arms. The PLACID trial of 464 patients with moderate COVID19 did not reveal significant differences in mortality or progression of the disease [22]. However, this trial was not blinded, and the antibodies' titer in the infused plasma was not determined a priori, resulting in 64/160 infused plasmas with undetectable antibodies, which may have interacted with the results. Additionally, and in contrast to other studies $[22,32,35]$ and to ours, no antibody response was observed in the intervention group. In the PlasmAr trial, no significant differences in mortality or clinical outcomes were observed between $\mathrm{CP}$ recipients and controls. However, this study involved patients with severe pneumonia but no life threatening disease [35].

Two other randomized trials on $\mathrm{CP}$ infusion are available only in a pre-print form. The CONCOVID trial [26] was prematurely closed after the enrollment of the first 86 patients because, at baseline, 53/66 patients had already detectable anti-SARS-CoV-2 neutralizing antibodies. No significant differences in mortality, duration of hospitalization and clinical improvement were observed between the $\mathrm{CP}$ and the control group. Another randomized study of 81 patients from Spain was prematurely stopped due to poor recruitment; it was shown that $\mathrm{CP}$ could be superior to standard of care [24].

An important finding in our study was the association of higher levels of anti-SARS$\mathrm{CoV}-2$ antibodies (above the median values) in the infused $\mathrm{CP}$ with significantly reduced risk of death. This association is in accordance with the recent publication by Joyner et al., where the death rate was significantly reduced for non-intubated patients receiving $\mathrm{CP}$ with high titers of antibodies [53]. However, in our study, due to the small number of patients, we could not demonstrate a discriminative effect between intubated and nonintubated patients.

Importantly, regarding secondary outcomes in our study, $\mathrm{CP}$ recipients compared to the control group demonstrated increased probability of extubation and exit from ICU. In addition, high antibody titers in the CP predicted a significantly higher rate of extubation and exit from ICU. These observations extend the beneficial effect of CP to intubated patients. Our findings are in accordance with other studies showing shorter duration in the ICU [29,39], reduction of the recovery time and duration of the infection for patients in the ICU [32] and reduction of mortality for intubated patients [38,44]; in contrast other trials, did not reveal a beneficial effect of CP for intubated patients [40,41,47].

However, $\mathrm{CP}$ infusion in our study was not associated with other secondary outcomes, like the clinical status at the end of follow-up, which was significantly associated with advanced age and the percentage of infiltrates in the CT scan indicative of more severe disease. These observations are in line with the results of randomized controlled trials demonstrating no significant differences in the clinical outcome between patients in the $\mathrm{CP}$ group and the controls $[22,24,26,35]$ as well as with the results of other non-randomized trials using comparison of $\mathrm{CP}$ recipients to matched controls, which failed to show an improvement in time to clinical recovery [41], hospitalization and ventilation times [40,46], or clinical improvement within 28 days [45]. In contrast, other studies of similar design to our study demonstrated in $\mathrm{CP}$ recipients an improvement in the supplemental oxygen requirements by day 14 compared to controls [30], improvement in the need for oxygen supply [37], and improvement in the clinical outcome for patients in ARDS [39].

Another important observation in our study was that the subgroup of patients negative for anti-SARS-CoV-2 antibodies at baseline showed a more robust antibody increase post infusion. One possible explanation could be that patients without detectable antibodies at baseline, associated with shorter duration of symptoms as shown by our data, had increased 
viral load, triggering a stronger endogenous antibody immune response, which was further intensified by CP infusion.

Regarding safety, our results are in agreement with other studies of CP infusion showing that it is a safe procedure. In the large trial from the US regarding the FDA expanded Access Program, CP infused in 20,000 hospitalized patients demonstrated low incidence of serious AEs, including transfusion reaction in $<1 \%$, thromboembolic or thrombotic events in $<1 \%$ and cardiac events in $\sim 3 \%$ [57]. No cases of antibody-dependent enhancement (ADE) were found in our study, in accordance with previous reports [25,28,33,34]. ADE represents a well-recognized effect in many viral illnesses [58,59] and is characterized by the facilitation of viral entry into the cells by antibodies or the enhancement of viral toxicity by antibodies [60].

Our study has several limitations. Although the controls were retrospectively selected by propensity score matching, the conclusions drawn are not as robust as through prospective randomized placebo-controlled trials. In addition, the serial changes in laboratory parameters and the antibody response in the control group were not determined since it was a retrospective comparison.

\section{Conclusions}

In conclusion, in this prospective multicenter phase II study, we show through multivariate analysis that $\mathrm{CP}$ infusion compared to a matched control group was associated with a significant reduction of the risk of death and a significantly improved overall survival by Kaplan-Meir analysis. Within a median follow-up of 28.5 days, 57/59 patients remained alive and 56 were discharged from hospital fully recovered, with a median hospital stay of 15 days. The death rate in the CP group was $3.4 \%$ vs. $13.6 \%$ in the control group. At the end of follow-up, 56/59 (94.9\%) in the intervention group were discharged compared to 51/59 $(86.4 \%)$ in the control group; however, this difference was not statistically significant. In addition, $13 / 59(22.0 \%)$ of patients in the control group exited ICU vs. $2 / 59(3.4 \%)(p=0.014)$ in the control group. A significant association between CP infusion and extubation or exit from ICU was also noted. High antibody levels in the CP were also associated with significantly improved OS, as shown by multivariate analysis, and with a higher rate of extubation and exit from ICU. CP infusion was safe and side effects were mild and easily managed. These encouraging data need confirmation by randomized controlled trials.

Supplementary Materials: The following are available online at https:/ / www.mdpi.com/article/10 $.3390 /$ microorganisms $9040806 /$ s1, Figure S1. Trend of SOFA score and laboratory parameters in the recipients following CP infusion: (a) SOFA, (b) Lymphocytes, (c) Platelets, (d) CRP, (e) ferritin, (h) Fibrinogen, (g) LDH, (h) IL-6, (i) Ct values of the PCR for SARS-CoV-2. Table S1. Results of univariate regression analyses for the association between baseline characteristics and secondary outcomes.

Author Contributions: Conceptualization: V.P., M.-A.D., G.N.P., E.T., M.P. (Marianna Politou), S.T.; investigation: V.P., A.B. (Anthi Bouhla), M.R., D.S., T.P.T., A.A., E.T., A.M., S.G.P., M.P. (Marianna Politou), A.K., I.K., G.P., E.J., E.K., S.G., S.K., X.H., J.B., R.B., M.P. (Maria Pagoni), I.T., E.G., S.L., K.S., A.B. (Aristotelis Bamias); data analysis and visualization: V.P., A.B. (Anthi Bouhla), T.P.T., M.R., B.K.F.; writing-review and editing: V.P., T.P.T., E.T., M.-A.D., G.N.P., B.K.F.; project administration: V.P., M.-A.D., E.T., A.B. (Anthi Bouhla), B.K.F., G.N.P. All authors have read and agreed to the published version of the manuscript.

Funding: This research received no external funding. This work was supported in part by SYNENOSIS and by the Intramural Research Program of the National Cancer Institute to G.N.P and B.K.F. with Federal funds from the National Cancer Institute, National Institutes of Health.

Institutional Review Board Statement: The study was conducted according to the guidelines of the Declaration of Helsinki, and approved by the local Ethics Committees of all participating hospitals.

Informed Consent Statement: Informed consent was obtained from all subjects involved in the study.

Data Availability Statement: The data presented in this study are available on request from the corresponding author. 
Acknowledgments: We thank T. Jones for administrative support; L.D. Esposito and J. Jones (ATRF, NCI) for SARS-CoV-2 proteins; T. Hatziioanou for pseudotype virus reagents and discussions.

Conflicts of Interest: The authors declare no conflict of interest.

\section{References}

1. World Health Organization (WHO). Report of the WHO-China Joint Mission on Coronavirus Disease 2019 (COVID-19). Available online: https: / / www.who.int/publications-detail/report-of-the-who-china-joint-mission-on-coronavirus-disease-2019-(covid19) (accessed on 1 March 2020).

2. European Centre for Disease Prevention and Control. Novel Coronavirus Disease 2019 (COVID-19) Pandemic: Increased Transmission in the EU/EEA and the UK-Sixth Update-12 March 2020; European Centre for Disease Prevention and Control: Stockholm, Sweden, 2020.

3. Zhou, P.; Yang, X.L.; Wang, X.G.; Hu, B.; Zhang, L.; Zhang, W.; Si, H.R.; Zhu, Y.; Li, B.; Huang, C.L.; et al. A pneumonia outbreak associated with a new coronavirus of probable bat origin. Nature 2020, 579, 270-273. [CrossRef]

4. Karpiński, T.M.; Ożarowski, M.; Seremak-Mrozikiewicz, A.; Wolski, H.; Wlodkowic, D. The 2020 race towards SARS-CoV-2 specific vaccines. Theranostics 2021, 11, 1690-1702. [CrossRef]

5. Datta, P.K.; Liu, F.; Fischer, T.; Rappaport, J.; Qin, X. SARS-CoV-2 pandemic and research gaps: Understanding SARS-CoV-2 interaction with the ACE2 receptor and implications for therapy. Theranostics 2020, 10, 7448-7464. [CrossRef]

6. Richardson, S.; Hirsch, J.S.; Narasimhan, M.; Crawford, J.M.; McGinn, T.; Davidson, K.W.; Barnaby, D.P.; Becker, L.B.; Chelico, J.D.; Cohen, S.L.; et al. Presenting Characteristics, Comorbidities, and Outcomes Among 5700 Patients Hospitalized With COVID-19 in the New York City Area. JAMA 2020, 323, 2052-2059. [CrossRef] [PubMed]

7. Wu, Z.; McGoogan, J.M. Characteristics of and Important Lessons From the Coronavirus Disease 2019 (COVID-19) Outbreak in China: Summary of a Report of 72314 Cases From the Chinese Center for Disease Control and Prevention. JAMA 2020, 323, 1239-1242. [CrossRef]

8. Chen, T.; Wu, D.; Chen, H.; Yan, W.; Yang, D.; Chen, G.; Ma, K.; Xu, D.; Yu, H.; Wang, H.; et al. Clinical characteristics of 113 deceased patients with coronavirus disease 2019: Retrospective study. BMJ 2020, 368, m1091. [CrossRef] [PubMed]

9. Arentz, M.; Yim, E.; Klaff, L.; Lokhandwala, S.; Riedo, F.X.; Chong, M.; Lee, M. Characteristics and Outcomes of 21 Critically Ill Patients With COVID-19 in Washington State. JAMA 2020, 323, 1612-1614. [CrossRef] [PubMed]

10. Danzi, G.B.; Loffi, M.; Galeazzi, G.; Gherbesi, E. Acute pulmonary embolism and COVID-19 pneumonia: A random association? Eur. Heart J. 2020, 41, 1858. [CrossRef] [PubMed]

11. Zhang, Y.; Xiao, M.; Zhang, S.; Xia, P.; Cao, W.; Jiang, W.; Chen, H.; Ding, X.; Zhao, H.; Zhang, H.; et al. Coagulopathy and Antiphospholipid Antibodies in Patients with Covid-19. N. Engl. J. Med. 2020, 382, e38. [CrossRef] [PubMed]

12. Beigel, J.H.; Tomashek, K.M.; Dodd, L.E. Remdesivir for the Treatment of Covid-19-Preliminary Report. Reply. N. Engl. J. Med. 2020, 383, 994. [CrossRef]

13. Horby, P.; Lim, W.S.; Emberson, J.R.; Mafham, M.; Bell, J.L.; Linsell, L.; Staplin, N.; Brightling, C.; Ustianowski, A.; Elmahi, E.; et al. Dexamethasone in Hospitalized Patients with Covid-19. N. Engl. J. Med. 2021, 384, 693-704. [CrossRef]

14. Lopes, M.I.; Bonjorno, L.P.; Giannini, M.C.; Amaral, N.B.; Menezes, P.I.; Dib, S.M.; Gigante, S.L.; Benatti, M.N.; Rezek, U.C.; Emrich-Filho, L.L.; et al. Beneficial effects of colchicine for moderate to severe COVID-19: A randomised, double-blinded, placebo-controlled clinical trial. RMD Open 2021, 7, e001455. [CrossRef] [PubMed]

15. Psaltopoulou, T.; Sergentanis, T.N.; Pappa, V.; Politou, M.; Terpos, E.; Tsiodras, S.; Pavlakis, G.N.; Dimopoulos, M.A. The Emerging Role of Convalescent Plasma in the Treatment of COVID-19. Hemasphere 2020, 4, e409. [CrossRef] [PubMed]

16. Cheng, Y.; Wong, R.; Soo, Y.O.; Wong, W.S.; Lee, C.K.; Ng, M.H.; Chan, P.; Wong, K.C.; Leung, C.B.; Cheng, G. Use of convalescent plasma therapy in SARS patients in Hong Kong. Eur. J. Clin. Microbiol. Infect. Dis. 2005, 24, 44-46. [CrossRef]

17. Lai, S.T. Treatment of severe acute respiratory syndrome. Eur. J. Clin. Microbiol. Infect. Dis. 2005, 24, 583-591. [CrossRef]

18. World Health Organization. Use of Convalescent Whole Blood or Plasma Collected from Patients Recovered from Ebola Virus Disease for Transfusion, As an Empirical Treatment during Outbreaks: Interim Guidance for National Health Authorities and Blood Transfusion Services; World Health Organization: Geneva, Switzerland, 2014.

19. Soo, Y.O.; Cheng, Y.; Wong, R.; Hui, D.S.; Lee, C.K.; Tsang, K.K.; Ng, M.H.; Chan, P.; Cheng, G.; Sung, J.J. Retrospective comparison of convalescent plasma with continuing high-dose methylprednisolone treatment in SARS patients. Clin. Microbiol. Infect. 2004, 10, 676-678. [CrossRef]

20. Rojas, M.; Rodríguez, Y.; Monsalve, D.M.; Acosta-Ampudia, Y.; Camacho, B.; Gallo, J.E.; Rojas-Villarraga, A.; Ramírez-Santana, C.; Díaz-Coronado, J.C.; Manrique, R.; et al. Convalescent plasma in Covid-19: Possible mechanisms of action. Autoimmun. Rev. 2020, 19, 102554. [CrossRef] [PubMed]

21. Abolghasemi, H.; Eshghi, P.; Cheraghali, A.M.; Imani Fooladi, A.A.; Bolouki Moghaddam, F.; Imanizadeh, S.; Moeini Maleki, M.; Ranjkesh, M.; Rezapour, M.; Bahramifar, A.; et al. Clinical efficacy of convalescent plasma for treatment of COVID-19 infections: Results of a multicenter clinical study. Transfus. Apher. Sci. 2020, 59, 102875. [CrossRef]

22. Agarwal, A.; Mukherjee, A.; Kumar, G.; Chatterjee, P.; Bhatnagar, T.; Malhotra, P. Convalescent plasma in the management of moderate covid-19 in adults in India: Open label phase II multicentre randomised controlled trial (PLACID Trial). BMJ 2020, 371, m3939. [CrossRef] 
23. Altuntas, F.; Ata, N.; Yigenoglu, T.N.; Basc1, S.; Dal, M.S.; Korkmaz, S.; Namdaroglu, S.; Basturk, A.; Hacibekiroglu, T.; Dogu, M.H.; et al. Convalescent plasma therapy in patients with COVID-19. Transfus. Apher. Sci. 2021, 60, 102955. [CrossRef]

24. Avendaño-Solà, C.; Ramos-Martínez, A.; Muñez-Rubio, E.; Ruiz-Antorán, B.; de Molina, R.M.; Torres, F.; Fernández-Cruz, A.; Callejas-Díaz, A.; Calderón, J.; Payares-Herrera, C.; et al. Convalescent Plasma for COVID-19: A multicenter, randomized clinical trial. medRxiv 2020. [CrossRef]

25. Duan, K.; Liu, B.; Li, C.; Zhang, H.; Yu, T.; Qu, J.; Zhou, M.; Chen, L.; Meng, S.; Hu, Y.; et al. Effectiveness of convalescent plasma therapy in severe COVID-19 patients. Proc. Natl. Acad. Sci. USA 2020, 117, 9490-9496. [CrossRef]

26. Gharbharan, A.; Jordans, C.C.E.; Geurtsvankessel, C.; den Hollander, J.G.; Karim, F.; Mollema, F.P.N.; Stalenhoef-Schukken, J.E.; Dofferhoff, A.; Ludwig, I.; Koster, A.; et al. Convalescent Plasma for COVID-19. A randomized clinical trial. medRxiv 2020. [CrossRef]

27. Joyner, M.J.; Senefeld, J.W.; Klassen, S.A.; Mills, J.R.; Johnson, P.W.; Theel, E.S.; Wiggins, C.C.; Bruno, K.A.; Klompas, A.M.; Lesser, E.R.; et al. Effect of Convalescent Plasma on Mortality among Hospitalized Patients with COVID-19: Initial Three-Month Experience. medRxiv 2020. [CrossRef]

28. Li, L.; Zhang, W.; Hu, Y.; Tong, X.; Zheng, S.; Yang, J.; Kong, Y.; Ren, L.; Wei, Q.; Mei, H.; et al. Effect of Convalescent Plasma Therapy on Time to Clinical Improvement in Patients With Severe and Life-threatening COVID-19: A Randomized Clinical Trial. JAMA 2020, 324, 460-470. [CrossRef]

29. Libster, R.; Pérez Marc, G.; Wappner, D.; Coviello, S.; Bianchi, A.; Braem, V.; Esteban, I.; Caballero, M.T.; Wood, C.; Berrueta, M.; et al. Early High-Titer Plasma Therapy to Prevent Severe Covid-19 in Older Adults. N. Engl. J. Med. 2021, 384, 610-618. [CrossRef] [PubMed]

30. Liu, S.T.H.; Lin, H.M.; Baine, I.; Wajnberg, A.; Gumprecht, J.P.; Rahman, F.; Rodriguez, D.; Tandon, P.; Bassily-Marcus, A.; Bander, J.; et al. Convalescent plasma treatment of severe COVID-19: A propensity score-matched control study. Nat. Med. 2020, 26, 1708-1713. [CrossRef] [PubMed]

31. U.S. Food and Drug Administration. Clinical Memorandum: EUA 26382: Emergency Use Authorization (EUA) Request (Original Request 8/12/20; Amended Request 8/23/20). 12 August 2020. Available online: https://www.fda.gov/media/141481 / download (accessed on 1 February 2021).

32. Rasheed, A.M.; Fatak, D.F.; Hashim, H.A.; Maulood, M.F.; Kabah, K.K.; Almusawi, Y.A.; Abdulamir, A.S. The therapeutic potential of convalescent plasma therapy on treating critically-ill COVID-19 patients residing in respiratory care units in hospitals in Baghdad, Iraq. Infez. Med. 2020, 28, 357-366.

33. Salazar, E.; Christensen, P.A.; Graviss, E.A.; Nguyen, D.T.; Castillo, B.; Chen, J.; Lopez, B.V.; Eagar, T.N.; Yi, X.; Zhao, P.; et al. Treatment of Coronavirus Disease 2019 Patients with Convalescent Plasma Reveals a Signal of Significantly Decreased Mortality. Am. J. Pathol. 2020, 190, 2290-2303. [CrossRef]

34. Shen, C.; Wang, Z.; Zhao, F.; Yang, Y.; Li, J.; Yuan, J.; Wang, F.; Li, D.; Yang, M.; Xing, L.; et al. Treatment of 5 Critically Ill Patients With COVID-19 With Convalescent Plasma. JAMA 2020, 323, 1582-1589. [CrossRef]

35. Simonovich, V.A.; Burgos Pratx, L.D.; Scibona, P.; Beruto, M.V.; Vallone, M.G.; Vázquez, C.; Savoy, N.; Giunta, D.H.; Pérez, L.G.; Sánchez, M.D.L.; et al. A Randomized Trial of Convalescent Plasma in Covid-19 Severe Pneumonia. N. Engl. J. Med. 2021, 384, 619-629. [CrossRef]

36. Ye, M.; Fu, D.; Ren, Y.; Wang, F.; Wang, D.; Zhang, F.; Xia, X.; Lv, T. Treatment with convalescent plasma for COVID-19 patients in Wuhan, China. J. Med. Virol. 2020, 92, 1890-1901. [CrossRef]

37. Shenoy, A.G.; Hettinger, A.Z.; Fernandez, S.J.; Blumenthal, J.; Baez, V. Early mortality benefit with COVID-19 convalescent plasma: A matched control study. Br. J. Haematol. 2021, 192, 706-713. [CrossRef] [PubMed]

38. Budhiraja, S.; Dewan, A.; Aggarwal, R.; Singh, O.; Juneja, D.; Pathak, S.; Singh, Y.P.; Gupta, A.; Rai, R.; Indrayan, A.; et al. Effectiveness of convalescent plasma in Indian patients with COVID-19. Blood Cells Mol. Dis. 2021, 88, 102548. [CrossRef]

39. Allahyari, A.; Seddigh-Shamsi, M.; Mahmoudi, M.; Amel Jamehdar, S.; Amini, M.; Mozdourian, M.; Javidarabshahi, Z.; Eslami Hasan Abadi, S.; Amini, S.; Sedaghat, A.; et al. Efficacy and safety of convalescent plasma therapy in severe COVID-19 patients with acute respiratory distress syndrome. Int. Immunopharmacol. 2021, 93, 107239. [CrossRef] [PubMed]

40. Tworek, A.; Jaroń, K.; Uszyńska-Kałuża, B.; Rydzewski, A.; Gil, R.; Deptała, A.; Franek, E.; Wójtowicz, R.; Życińska, K.; Walecka, I.; et al. Convalescent plasma treatment is associated with lower mortality and better outcomes in high-risk COVID-19 patients-propensity-score matched case-control study. Int. J. Infect. Dis. 2021, 105, 209-215. [CrossRef] [PubMed]

41. AlShehry, N.; Zaidi, S.Z.A.; AlAskar, A.; Al Odayani, A.; Alotaibi, J.M.; AlSagheir, A.; Al-Eyadhy, A.; Balelah, S.; Salam, A.; Zaidi, A.R.Z.; et al. Safety and Efficacy of Convalescent Plasma for Severe COVID-19: Interim Report of a Multicenter Phase II Study from Saudi Arabia. Saudi J. Med. Med. Sci. 2021, 9, 16-23. [CrossRef] [PubMed]

42. Franchini, M.; Glingani, C.; Morandi, M.; Corghi, G.; Cerzosimo, S.; Beduzzi, G.; Storti, A.; Di Stasi, V.; Rastrelli, G.; Vignozzi, L.; et al. Safety and efficacy of convalescent plasma in elderly COVID-19 patients: The RESCUE trial. Mayo Clin. Proc. Innov. Qual. Outcomes 2021. [CrossRef]

43. Balcells, M.E.; Rojas, L.; Le Corre, N.; Martínez-Valdebenito, C.; Ceballos, M.E.; Ferrés, M.; Chang, M.; Vizcaya, C.; Mondaca, S.; Huete, Á.; et al. Early versus deferred anti-SARS-CoV-2 convalescent plasma in patients admitted for COVID-19: A randomized phase II clinical trial. PLoS Med. 2021, 18, e1003415. [CrossRef] 
44. Donato, M.L.; Park, S.; Baker, M.; Korngold, R.; Morawski, A.; Geng, X.; Tan, M.; Ip, A.; Goldberg, S.; Rowley, S.; et al. Clinical and laboratory evaluation of patients with SARS-CoV-2 pneumonia treated with high-titer convalescent plasma. JCI Insight 2021, 6. [CrossRef]

45. Kurtz, P.; Righy, C.; Gadelha, M.; Bozza, F.A.; Bozza, P.T.; Gonçalves, B.; Bastos, L.S.L.; Vale, A.M.; Higa, L.M.; Castilho, L.; et al. Effect of Convalescent Plasma in Critically Ill Patients With COVID-19: An Observational Study. Front. Med. (Lausanne) 2021, 8, 630982. [CrossRef] [PubMed]

46. Sostin, O.V.; Rajapakse, P.; Cruser, B.; Wakefield, D.; Cruser, D.; Petrini, J. A matched cohort study of convalescent plasma therapy for COVID-19. J. Clin. Apher. 2021. [CrossRef] [PubMed]

47. Klapholz, M.; Pentakota, S.R.; Zertuche, J.P.; McKenna, M.; Roque, W.; Forsberg, M.; Packer, J.; Lal, D.S.; Dever, L. Matched Cohort Study of Convalescent COVID-19 Plasma Treatment in Severely or Life Threateningly Ill COVID-19 Patients. Open Forum Infect. Dis. 2021, 8, ofab001. [CrossRef]

48. FDA Issues Emergency Use Authorization for Convalescent Plasma as Potential Promising COVID-19 Treatment, An-other Achievement in Administration's Fight Against Pandemic. Available online: https://www.fda.gov/news-events/pressannouncements / fda-issues-emergency-use-authorization-convalescent-plasma-potential-promising-covid-19-treatment (accessed on 1 February 2021).

49. FDA In Brief: FDA Updates Emergency Use Authorization for COVID-19 Convalescent Plasma to Reflect New Data. Available online: https://www.fda.gov/news-events/fda-brief/fda-brief-fda-updates-emergency-use-authorization-covid-19 -convalescent-plasma-reflect-new-data\#: \{\}:text=Today $\% 2 C \% 20$ the $\% 20 F D A \% 20$ is $\% 20$ revising,patients $\% 20$ who $\% 20$ have $\% 20$ impaired\%20humoral (accessed on 1 February 2021).

50. Terpos, E.; Politou, M.; Sergentanis, T.N.; Mentis, A.; Rosati, M.; Stellas, D.; Bear, J.; Hu, X.; Felber, B.K.; Pappa, V.; et al. Anti-SARS-CoV-2 Antibody Responses in Convalescent Plasma Donors Are Increased in Hospitalized Patients; Subanalyses of a Phase 2 Clinical Study. Microorganisms 2020, 8, 1885. [CrossRef]

51. Schmidt, F.; Weisblum, Y.; Muecksch, F.; Hoffmann, H.H.; Michailidis, E.; Lorenzi, J.C.C.; Mendoza, P.; Rutkowska, M.; Bednarski, E.; Gaebler, C.; et al. Measuring SARS-CoV-2 neutralizing antibody activity using pseudotyped and chimeric viruses. J. Exp. Med. 2020, 217. [CrossRef]

52. Jones, A.E.; Trzeciak, S.; Kline, J.A. The Sequential Organ Failure Assessment score for predicting outcome in patients with severe sepsis and evidence of hypoperfusion at the time of emergency department presentation. Crit. Care Med. 2009, 37, 1649-1654. [CrossRef] [PubMed]

53. Joyner, M.J.; Carter, R.E.; Senefeld, J.W.; Klassen, S.A.; Mills, J.R.; Johnson, P.W.; Theel, E.S.; Wiggins, C.C.; Bruno, K.A.; Klompas, A.M.; et al. Convalescent Plasma Antibody Levels and the Risk of Death from Covid-19. N. Engl. J. Med. 2021, 384, 1015-1027. [CrossRef]

54. Liu, M.; Chen, Z.; Dai, M.Y.; Yang, J.H.; Chen, X.B.; Chen, D.; You, H.; Guo, X.; Leng, Y.; Yu, L.; et al. Lessons learned from early compassionate use of convalescent plasma on critically ill patients with Covid-19. Transfusion 2020, 60, 2210-2216. [CrossRef]

55. Perotti, C.; Baldanti, F.; Bruno, R.; Del Fante, C.; Seminari, E.; Casari, S.; Percivalle, E.; Glingani, C.; Musella, V.; Belliato, M.; et al. Mortality reduction in 46 severe Covid-19 patients treated with hyperimmune plasma. A proof of concept single arm multicenter trial. Haematologica 2020, 105, 2834-2840. [CrossRef]

56. Cantore, I.; Valente, P. Convalescent plasma from COVID 19 patients enhances intensive care unit survival rate. A preliminary report. Transfus. Apher. Sci. 2020, 59, 102848. [CrossRef]

57. Joyner, M.J.; Bruno, K.A.; Klassen, S.A.; Kunze, K.L.; Johnson, P.W.; Lesser, E.R.; Wiggins, C.C.; Senefeld, J.W.; Klompas, A.M.; Hodge, D.O.; et al. Safety Update: COVID-19 Convalescent Plasma in 20,000 Hospitalized Patients. Mayo Clin. Proc. 2020, 95, 1888-1897. [CrossRef] [PubMed]

58. Katzelnick, L.C.; Gresh, L.; Halloran, M.E.; Mercado, J.C.; Kuan, G.; Gordon, A.; Balmaseda, A.; Harris, E. Antibody-dependent enhancement of severe dengue disease in humans. Science 2017, 358, 929-932. [CrossRef] [PubMed]

59. Smatti, M.K.; Al Thani, A.A.; Yassine, H.M. Viral-Induced Enhanced Disease Illness. Front. Microbiol. 2018, 9, 2991. [CrossRef]

60. Taylor, A.; Foo, S.S.; Bruzzone, R.; Dinh, L.V.; King, N.J.; Mahalingam, S. Fc receptors in antibody-dependent enhancement of viral infections. Immunol. Rev. 2015, 268, 340-364. [CrossRef] [PubMed] 